\title{
The Comparative Study of Pure Mesoporous Silica SBA-15 and CPTMS-SBA-15 Adsorption of Pb Heavy Metal
}

\author{
Jaka Fajar Fatriansyah ${ }^{1}$, Donanta Dhaneswara ${ }^{1}$, Frans Wensten Situmorang ${ }^{1 *}$, Aloysius \\ Brahmarsi ${ }^{1}$, Farhan Delayori ${ }^{1}$, Siti Utami A.A. ${ }^{1}$, and Dessy Prawesti Kusumawardhani ${ }^{1}$. \\ ${ }^{1}$ Metallurgical and Materials Engineering, Faculty of Engineering, Universitas Indonesia, Kampus UI \\ Depok, Jawa Barat, 16424 \\ Corresponding author: fajar@metal.ui.ac.id
}

\begin{abstract}
Mesoporous silica SBA-15 has been successfully synthesized and its surface has been modified/functionalized with CPTMS. The making of pure SBA-15 was operated at an optimized concentration of Pluronic 123 surfactant at $60 \mathrm{mM}$ which yields surface area of $831.996 \mathrm{~m}^{2} / \mathrm{g}$ determined by BET. The modified SBA-15, SBA-15+CPTMS have a lower surface area in comparison with neat SBA-15. In this study, SBA$15+$ CPTMS have a surface area of about $711.061 \mathrm{~m}^{2} / \mathrm{g}$. This very high surface area was utilized to remove the $\mathrm{Pb}$ in industrial wastewater using laboratory made water samples. Despite lower surface area and pore diameter of SBA-15+CPTMS in comparison with pure SBA-15, the effectivity of SBA-15+CPTMS in lead adsorption much higher than mesoporous silica SBA-15 especially at a lower concentration of adsorbents. In this paper, we compared the percentage of $\mathrm{Pb}$ removal using mesoporous silica SBA-15 and CPTMS-SBA-15 systems. It was found at a low concentration of adsorbent, CPTMS-SBA-15 yields three times percentage of $\mathrm{Pb}$ removal than pure SBA-15. However, at high concentration of adsorbent, CPTMS-SBA-15 percentage of $\mathrm{Pb}$ removal is just slightly higher than the pure SBA-15 percentage of $\mathrm{Pb}$ removal.
\end{abstract}

Keywords: mesoporous silica, adsorption, heavy metal waste

\section{Introduction}

The rapid economic development at the end of the 20th century brings prosperity and wealth for many countries, especially in G-20 countries. One of the side effects of this development is the immense water pollution by the industrial waste which contains heavy metals. These toxic materials can bring horrendous health problems for aquatic ecosystems, animals, human as well as environment. The World Health Organization (WHO) had identified the inorganic pollutants which are extremely dangerous for living things. The example of the lists is Arsenic, Cadmium, Chromium, Copper, Lead, Mercury and Zinc [Benaissa, 2008; Keith, 1979; Srivastava, 2010; Stafiej, 2007].

\footnotetext{
* Corresponding author: fajar@metal.ui.ac.id
} 
Mesoporous materials, especially silica based one, are one of promising nanotechnology materials that have many potential applications in the wide area. Recently, silica mesoporous has been used as advanced optics [Scott, 2001], biosensor [Radu, 2004], biomolecules adsorption [Katiyar, 2006], drug delivery [Mellaerts, 2008], membrane separation [Zornoza, 2009] and catalysis [Abdalla, 2012]. IUPAC has specifically defined that mesoporous silica material is a silica based materials with the distribution of mesopores (although micropores and macropores also exist) which the diameters are in the range of 2$500 \mathrm{~nm}$ [McCusker, 2001]. Because of its highly ordered mesostructures, this material has very high surface area and volume ratio, allowing diffusion and adsorption of larger molecules compared to zeolite or other micropores materials, and thus making this material suitable for catalysis and sorption application.

In this study, we focus on SBA-15, which is a mesoporous silica with a fine pore diameter arrangement and controllable pore diameter between 5 to $15 \mathrm{~nm}$, although other mesoporous silica also widely used such as MCM-41 or other MCM family and other SBA. SBA-15 was synthesized by Zhao et. al [1998, 2000] (named after the University of California, Santa Barbara). SBA-15 compared with older mesoporous silica has larger pores and thicker walls ( 3.1 to $6.4 \mathrm{~nm}$ ), these make SBA-15 yields has good thermal, mechanical stability and chemical resistance properties. Thus, all of these advantages make SBA-15 become a material which can be used for wide applications. The structure of SBA-15 is an ordered hexagonal and it was also synthesized using triblock copolymer. The surface area of neat SBA-15 could be up to $650 \mathrm{~m}^{2} / \mathrm{gr}$. In this study triblock copolymer was used as a template for SBA-15. It has an advantage which is much easier to synthesize the SBA-15. In this study, Pluronic 123, a triblock copolymer surfactant was used [Dhaneswara, 2016]. The pluronic 123 has the ability to create a long cylindrical micelle which is specifically appropriate to make SBA-15 with precursor silica Tetraethylorthosilicate/TEOS. The use of mesoporous silica SBA-15 in sorption application is connected with their high capacity in the adsorption mechanism.

In order to increase the effectivity of mesoporous silica SBA-15 in sorption application, modification of surface should be made. The common silane surface modification $n$ was operated using APTES $\left(\mathrm{C}_{9} \mathrm{H}_{23} \mathrm{NO}_{3} \mathrm{Si}, 3\right.$-aminopropyltriethoxysilane) [Li, 2011] and APTMS (3-aminopropyltrimethoxysilane) [Molina de la Torre, 2017]. In this manner, silanization process produces a terminal amine group $\left(-\mathrm{NH}_{2}\right)$ and thus the connection of $-\mathrm{NH}_{2}$ group is created providing single electron pair that makes possible to form complexes with heavy metal ions [Chong, 2003; Zhao, 2011]. In this study, to functionalize the surface of SBA-15 we used CPTMS (3-Chloropyltrimethoxysilane) as silanization agent. However, CPTMS does not have $\mathrm{NH}_{2}$, instead, it has a Chlor atom. Asgari et. al [Asgari, 2016] actually had functionalized mesoporous silica SBA-15 with CPTMS and THPP but they focused more on the role of THPP as a modifier. In this paper, we investigated the effect of CPTMS as functionalization/silanized agent of mesoporous silica $\mathrm{SBA}-15$ on the $\mathrm{Pb}$ adsorption effectivity through Adsorption Atomic spectroscopy (AAS) and BET results comparison.

\section{Experiment}

\subsection{Materials}

In order to synthesize mesoporous silica SBA-15, silica precursor Tetraethyorthosilicate/TEOS (Merck) and Surfactant Pluronic 123 (BASF) aa s template was used. $\mathrm{HCl} 2 \mathrm{M}$ (Merck), distilled water and ethanol were used as a solvent. All of the 
materials were used without further purification. CPTMS (3-Chloropyltrimethoxysilane) (Sigma Aldrich) and toluene for SBA-15 functionalization were used.

\subsection{Synthesis SBA-15 and functionalization}

We used sol-gel wet path in order to synthesize mesoporous silica SBA-15. The basic main block of mesoporous silica is silica and the wet template for example surfactant. The precursor of silica is TEOS (Tetraethyl orthosilicate/ $\left.\mathrm{Si}\left(\mathrm{OC}_{2} \mathrm{H}_{5}\right)_{4}\right)$ and the template is surfactant Pluronic 123 (triblock copolymer constituted of poly (ethylene oxide) (PEO) and poly (propylene oxide) (PPO)). The very acidic condition was used in the sol-gel method to ensure the self-assembly of silica occurs on the wet template. First, $5 \mathrm{ml}$ of et.OH was added to $31.25 \mathrm{gr}$ of TEOS and then the mixture was mixed under room temperature for 30 minutes. Then, $5 \mathrm{ml}$ et. $\mathrm{OH}$ was assorted with $10 \mathrm{ml} \mathrm{HCl}$ to make add acidity. This solution then was mixed again with et. $\mathrm{OH}(10 \mathrm{ml})$ and the addition of $50 \mathrm{ml}$ distilled water and they were mixed under room temperature for 30 minutes. Then, the mixed solution was refluxed at $70{ }^{\circ} \mathrm{C}$ for 120 minutes. The TEOS solution was ready to be used in a further step. Further, the surfactant template solution was synthesized. Based on optimum concentration according to Dhaneswara et. Al [Dhaneswara, 2016], the concentration of surfactant which used in this study was fixed at $60 \mathrm{mM}$. Then, the mixture of $\mathrm{HCl}(10 \mathrm{ml})$ and ethanol $(25$ $\mathrm{ml}$ ) was added by the surfactant. Next, Pluronic 123 solution was added dropwise into TEOS solution and it was continuously stirred until a wet gel was formed in the solution. The wet gel obtained from this process then was dried for an hour at $100^{\circ} \mathrm{C}$ and then was calcined for the addition of 300 minutes. Finally, the final product was ready for adsorption characterization. To functionalize mesoporous silica SBA-15 with CPTMS, we use the following procedure. Synthesized mesoporous silica SBA-15 was suspended and mixed in $50 \mathrm{~mL}$ toluene. CPTMS then was added dropwise into SBA-15-toluene mixture. The mixture of SBA-15 and CPTMS then was refluxed in a flask at around $100^{\circ} \mathrm{C}$ overnight. The precipitate which obtained was filtered and washed with toluene. The resulting material then was dried for 840 minutes at constant temperature $100^{\circ} \mathrm{C}$. The resulting material then was called as SBA-15-CPTMS. The chemical structure of CPTMS can be seen in figure 1.

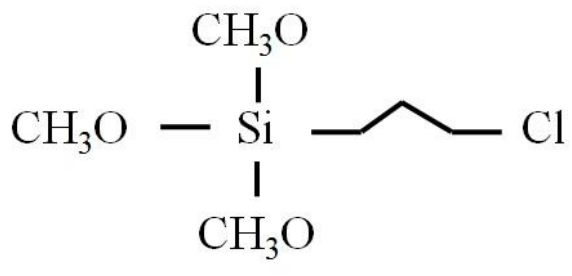

Fig. 1. Chemical structure of CPTMS. Instead of containing $\mathrm{NH} 2$ at the end of the structure as APTES and APTMS, CPTMS contains $\mathrm{Cl}$ as a substitute.

\subsection{Pb ion adsorption test}

In order to obtain the fix concentration of $\mathrm{Pb}$ at $100 \mathrm{mg} / \mathrm{L}$, lead ions were dissolved in pure water. $25 \mathrm{~mL}$ of lead ion solutions were settled in bottles and homogenized. SBA-15 as adsorbent was then added carefully into homogenized lead ion solutions with the concentrations of $0.2,0.5$ and $1 \mathrm{~g} / \mathrm{L}$. The mixtures then were stirred ( with the rate around $100 \mathrm{rpms}$ ) for 120 mins at room temperature. 


\subsection{Characterization}

In order to measure pore diameter, the surface area, and pore volume, the adsorption isotherm experiment was operated using Quantachrome adsorption-desorption equipment at $77 \mathrm{~K}$. The adsorbate which used in this characterization process is $\mathrm{N}_{2}$. In order to determine the specific surface area, we used Brunauer-Emmer-Teller (BET). In order to check the adsorption of $\mathrm{Pb}$ ions, we used Atomic Absorption Spectroscopy (AAS). The concentration of lead ions in solution can be extracted from the spectra observed from AAS.

\section{Results and discussion}

In this paper, we modified (functionalize) SBA-15 with CPTMS. CPTMS contains $\mathrm{Cl}$ at the end of the group instead of the amine as in APTES and APTMS. In this sense, we want to observe the effect of Chlor addition on the surface of mesoporous silica. First, we should measure the structural parameter (textural characteristics) of the pores. We used the BET method to calculate pore diameter (Kr87 method), surface area and pore volume. The results for SBA-15 and SBA-15+CPTMS can be seen in the table below.

Table 1. BET result of textural characteristics of samples

\begin{tabular}{|l|l|c|c|c|}
\hline No & Sample & Pore diameter & Surface Area & Pore volume \\
\hline 1 & $\begin{array}{l}\text { mesoporous silica } \\
\text { SBA-15 }\end{array}$ & $29.203 \AA$ & $831.996 \mathrm{~m}^{2} / \mathrm{g}$ & $265.161 \mathrm{cc} / \mathrm{g}$ \\
\hline 2 & SBA-15-CPTMS & $28.521 \AA$ & $711.061 \mathrm{~m}^{2} / \mathrm{g}$ & $199.649 \mathrm{cc} / \mathrm{g}$ \\
\hline
\end{tabular}

On table 1, it is shown that the surface is of CPTMS functionalized SBA-15 is significantly smaller than the surface area as well as its pore volume. The surface area and pore volume of SBA-15+CPTMS were diminished by $15 \%$ and $25 \%$ respectively in comparison to mesoporous silica SBA-15. These results are reflected on the sorption isotherm curve in which for SBA-15-CPTMS, the gas uptake much lower than the mesoporous silica SBA-15 curve of sorption isotherm (see figure 2). On figure 2 too, it can be seen that both samples show the sorption isotherms type IV and a hysteresis loop type H1 in the relative pressure range from 0.5 to 0.9 for untreated SBA-15 and 0.6 to 0.73 for SBA-15-CPTMS. Relatively unchanged curve, before and after functionalization of mesoporous silica SBA-15 indicating that there was no surface/pore structural alteration occurred. This result indicates that the uniform mesoporous structure of SBA-15 was relatively kept intact even after functionalization, even though smaller size of pore, diameter, and volume were observed in which indicating that the surface was modified. The reduce of those parameters can be explained as the functionalization agent or part of the reacted CPTMS were placed on the surface and inside the pores of SBA-15. The distribution of the size of the pore can be seen in figure 3. The result shows that the average pore size decreased although the distribution was almost similar. The less height of the peak for SBA-15+CPTMS in comparison with mesoporous silica SBA-15 demonstrates that the functionalization produces less order structure. This results in agreement with Chong et. al [Chong, 2003] when the silanized SBA-15 with APTES. In figure 4, we show TEM images for (a) mesoporous silica SBA-15 and (b) SBA-15+CPTMS. Nano-sized pores were observed for both samples. The CPTMS modified SBA-15 looks brighter due to the modification of the surface with Chlor and methyl. 
According to our samples FTIR results (shown in figure 4), we suggest the SBA$15+$ CPTMS structure as in figure 5. From FTIR spectra, it can be shown that there are symmetric-asymmetric stretching of C-H bonds $\left(2950-2850 \mathrm{~cm}^{-1}\right)$, the vibration of Si-C bonds $\left(722 \mathrm{~cm}^{-1}\right)$ and $\mathrm{C}-\mathrm{Cl}$ bonds $\left(500 \mathrm{~cm}^{-1}\right)$.

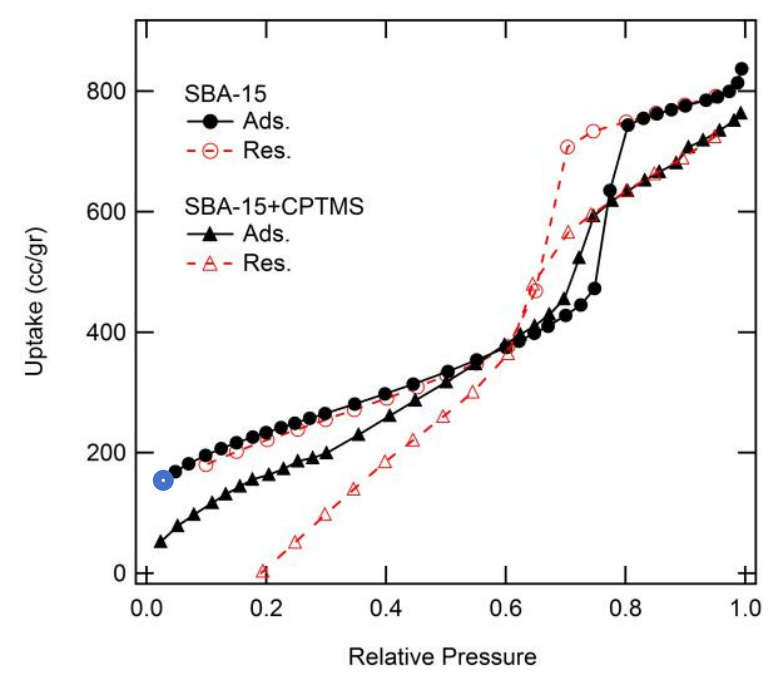

Fig. 2. The adsorption and desorption isotherm curves of mesoporous silica SBA-15 and SBA-15CPTMS. Both curves show the type IV sorption isotherm with type H1 of hysteresis curves.

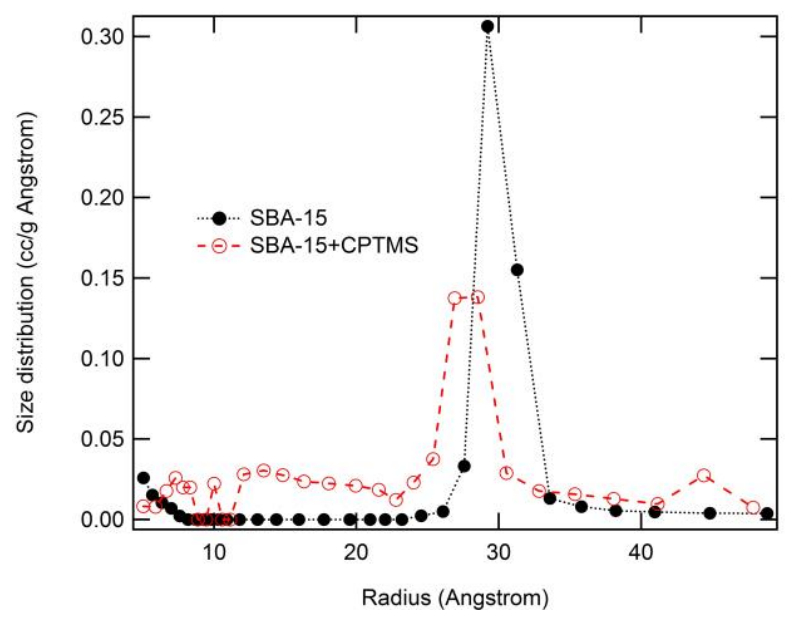

Fig. 3. The size distribution of mesoporous silica SBA-15 and SBA-15+CPTMS pores. SBA$15+$ CPTMS has a smaller size of pore size in comparison with mesoporous silica SBA-15, while their distribution is somewhat similar. 


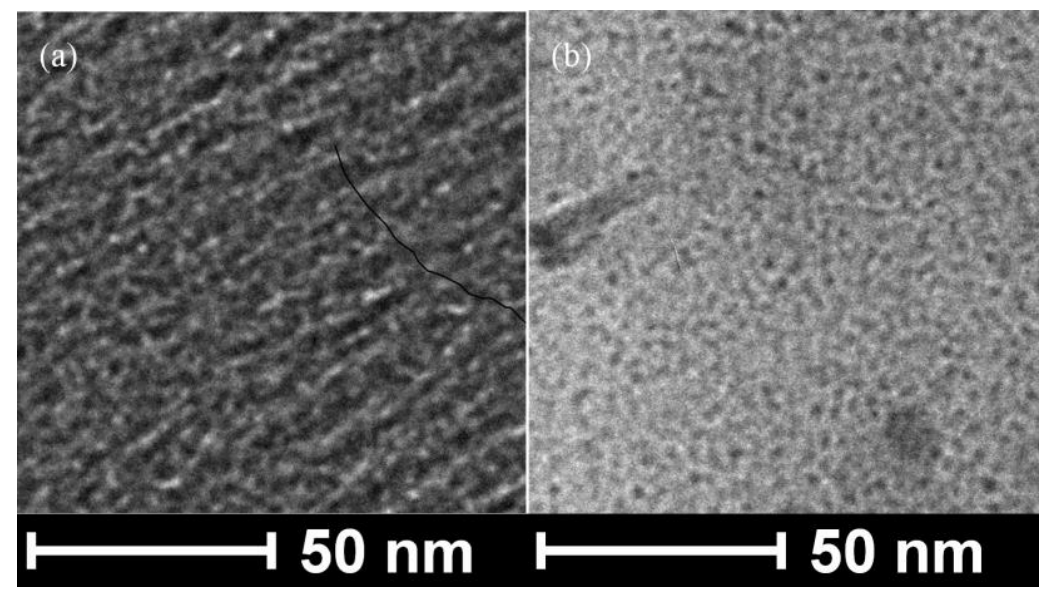

Fig. 4. TEM images for (a) mesoporous silica SBA-15 and (b) SBA-15 CPTMS. Nano-sized pores were observed for both samples. The CPTMS modified SBA-15 looks brighter due to the modification of the surface with Chlor and methyl.

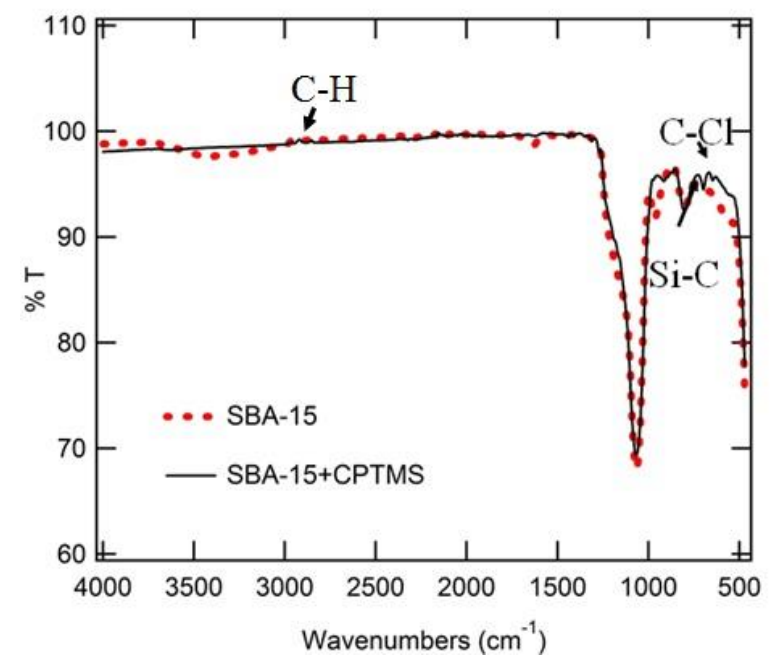

Fig. 5. FTIR spectra of mesoporous silica SBA-15 and SBA-15+CPTMS samples. Symmetricasymmetric stretching of C-H bonds $\left(2950-2850 \mathrm{~cm}^{-1}\right)$, the vibration of Si-C bonds $\left(722 \mathrm{~cm}^{-1}\right)$ and C$\mathrm{Cl}$ bonds $\left(500 \mathrm{~cm}^{-1}\right)$. 


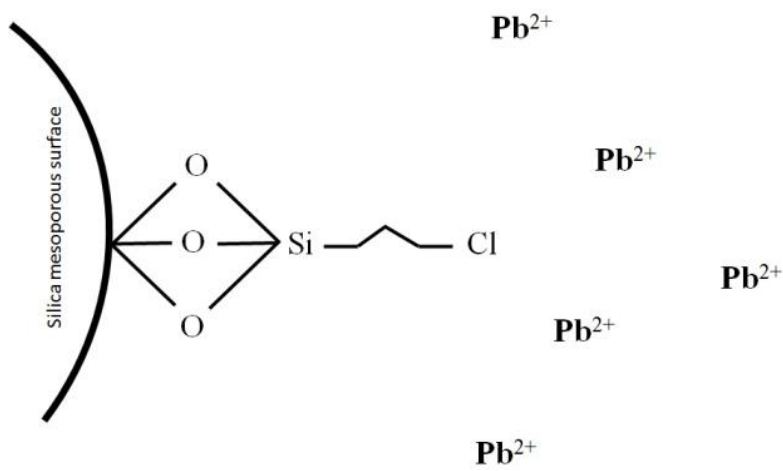

Fig. 6. Possible structure of SBA-15-CPTMS. The grafted part of CPTMS was attached in the silica surface in the sea of $\mathrm{Pb}$ ions.

Now we discuss lead removal in adsorption experiment results. The results are shown in figure 6 and table2. The amount of $\mathrm{Pb}$ removal was calculated by measuring the percentage of residual $\mathrm{Pb}$ with respect to the total amount of the original concentration of $\mathrm{Pb}$. The results show that $\mathrm{Pb}$ removal is somewhat higher for SBA-15+CPTMS in comparison with pure SBA-15 especially at a concentration of adsorbent of 0.2 and $0.5 \mathrm{~g} / \mathrm{L}$. For a concentration of adsorbent $1 \mathrm{~g} / \mathrm{L}$, the difference of Pb removal value for SBA-15 and SBA-15+CPTMS is somewhat narrower. For both samples, in respect to the adsorbent, the amount of $\mathrm{Pb}$ removal is saturated around $0.8 \mathrm{~g} / \mathrm{L}$ concentration of adsorbent.

Here we notice that the surface area of SBA-15 is higher than ABA-15+CPTMS, the effectivity in adsorbing heavy metal (in this case $\mathrm{Pb}$ ) is somewhat higher. This phenomenon can be explained as follows. The functionalization/modification of mesoporous silica SBA15 surface was reducing the pore size/diameter and surface area due to the fact that BET surface and volume are standardized towards neat silica weights as shown by Muresenau et. al [Muresenau, 2006]. Thus, as expected, the BET surface area was greatly decreasing during functionalization. In addition, the CPTMS/grafted/silanized substrate may be located inside the pores not only on the surface. However, smaller surface area and pore diameter do not translate to the lower adsorption effectivity towards heavy metal as we demonstrated. The functionalization of SBA-15 yields the $\mathrm{O}-\mathrm{Si}_{-} \mathrm{Cl}^{-}$bridge. This bridge may capture and/or adsorb $\mathrm{Pb}$ better in comparison with the only $\mathrm{Si}-\mathrm{O}$ surface. We found that the effective mesoporous silica SBA-15 and SBA-15+CPTMS for Pb adsorption are around $0.8 \mathrm{~g} / \mathrm{L}$ for both samples. Here we restrict our paper to this stage of an experiment since our purpose only compares the effectivity of CPTMS functionalization of SBA-15.

Table 2. Pb removal of mesoporous silica SBA-15 and SBA-15-CPTMS.

\begin{tabular}{|l|l|l|l|}
\hline No & Sample & \multicolumn{2}{|l|}{ Pb removal (\%) } \\
\hline 1 & mesoporous silica & $0.2 \mathrm{~g} / \mathrm{L}$ & 59.40 \\
\cline { 3 - 4 } & \multirow{2}{*}{ SBA-15 } & $0.5 \mathrm{~g} / \mathrm{L}$ & 55.20 \\
\cline { 3 - 4 } & & $1.0 \mathrm{~g} / \mathrm{L}$ & 86.84 \\
\hline 2 & \multirow{2}{*}{ SBA-15-CPTMS } & $0.2 \mathrm{~g} / \mathrm{L}$ & 85.45 \\
\cline { 3 - 4 } & & $0.5 \mathrm{~g} / \mathrm{L}$ & 86.69 \\
\cline { 3 - 4 } & & $1.0 \mathrm{~g} / \mathrm{L}$ & 89.96 \\
\hline
\end{tabular}




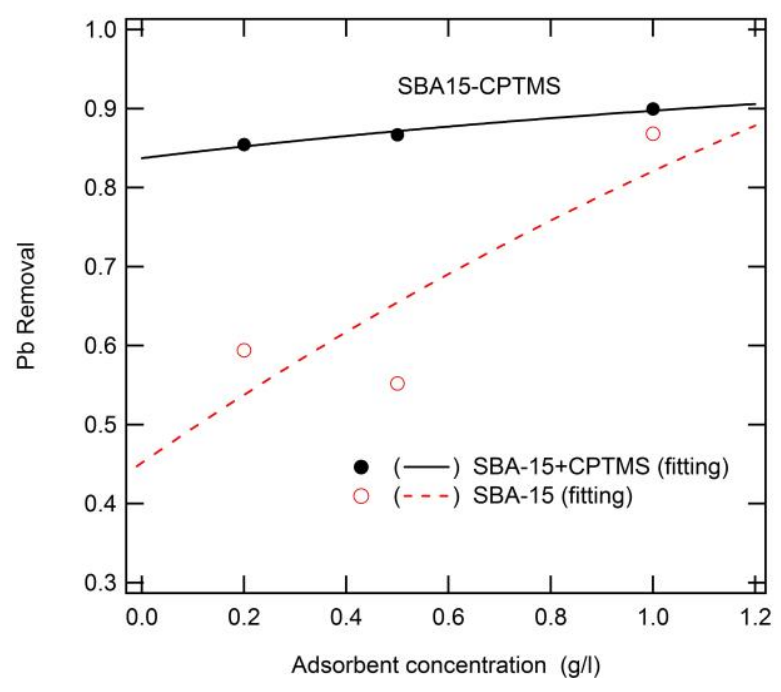

Fig. 6. Lead removal with the mesoporous silica SBA-15 and SBA-15+CPTMS adsorbents. The results show that SBA-15+CPTMS has higher lead removal than pure SBA-15 although, at high concentration of adsorbent, both adsorbents has relatively close value.

\section{Conclusions}

We had synthesized mesoporous silica SBA-15 and functionalized SBA-15 with CPTMS. We found that pore diameter, volume and surface area for SBA-15+CPTMS is somewhat smaller than SBA-15. This is partly due to the existence of a part of CPTMS/grafted CPTMS inside pore and surface. However, the less surface area value does not translate to the lower effectivity towards the adsorption of $\mathrm{Pb}$. Here we found that SBA-15+CPTMS has higher effectivity for adsorbing $\mathrm{Pb}$ in comparison with mesoporous silica SBA-15, although at high concentration of adsorbents both samples show a smaller difference. Both samples have maximum effectivity at a concentration of adsorbent of $0.8 \mathrm{~g} / \mathrm{L}$.

This writing is supported by DRPM (Direktorat Riset dan Pengembangan Masyarakat Universitas Indonesia) under PITTA (Publikasi Terindeks Internasional Untuk Tugas Akhir) 2017 grant with the number of contract 2420/UN2.2R3.1/PPM.00.01/2018.

\section{References}

1. Benaiss, H, Alexandria, Egypt, 18-21 December 2008.

2. Keith, L. H.; Telliard, W., Environ. Sci. Technol. 1979, 13, 416.

3. Srivastava, S; Goyal, P, Springer-Verlag. ISBN 978-3-642-11329-1. (2010).

4. Stafiej, A.; Pyrzynska, K. Adsorption of heavy metal ions with carbon nanotubes. Sep. Purif. Technol. 2007, 58, 49-52.

5. Scott, Brian J., Gernot Wirnsberger, and Galen D. Stucky., Chemistry of materials 13.10, 3140-3150. (2001)

6. Radu, D. R., Lai, C., Jeftinija, K., Rowe, E. W., Jeftinija, S., \& Lin, Victor S. Y., Journal of the Americal Chemical Society. 126 (41): 13216-13217, 2004. 
7. Katiyar, A., Yadav, S., Panagiotis, G., Neville, S., Pinto, G., Journal of Chromatography. 1122 (1-2): 13-20. 2006

8. Mellaerts, R., Mols, R., Kayaert, P., Annaert, P., Van Humbeeck, J., Van Den M. G., Martens, J. A., Augustijns, P., International Journal of Pharmaceutics. 357 (12): 169-79, 2008.

9. Zornoza, B., Irusta, S., Téllez, C., \& Coronas, J., Langmuir, 25(10), 5903-5909, 2009.

10. Abdalla, Z. E. A., and Baoshan L., Chemical Engineering Journal, 200, 113-121, 2012.

11. McCusker, L. B., Liebau, F., \& Engelhardt, G., Pure and Applied Chemistry, 73(2), 381-394, 2001.

12. Zhao, D., Feng, J., Huo, Q., Melosh, N., Fredrickson, G. H., Chmelka, B. F., \& Stucky, G. D., Science, 279.5350: 548-552, 1998.

13. Zhao, D., Sun, J., Li, Q., \& Stucky, G. D., Chemistry of materials, 12.2: 275-279, 2000.

14. Dhaneswara, D., \& Sofyan, N., International Journal Of Technology, 7(6), 10091015, (2016).

15. Li, G., Wang, B., Sun, Q., Xu, W., \& Han, Y., Microporous and Mesoporous Materials. 252 (2017).

16. Molina de la Torre, Jesús Ángel, and Ana Carmen Albéniz., European Journal of Inorganic Chemistry, 22 (2017).

17. Maria Chong, A. S., and X. S. Zhao., The Journal of Physical Chemistry B $\mathbf{1 0 7 . 4 6}$ (2003): 12650-12657.

18. Zhao, Y., Gao, Q., Tang, T., Xu, Y., \& Wu, D., Materials Letters, 65(6), 10451047. (2011). 